\title{
Organometallic complexes of the platinum metals: Synthesis, structure, and catalytic applications
}

\author{
PIYALI PAUL and SAMARESH BHATTACHARYA* \\ Department of Chemistry, Inorganic Chemistry Section, Jadavpur University, Kolkata 700 032, India \\ e-mail: samaresh_b@hotmail.com
}

\begin{abstract}
Reaction of a group of $\mathrm{N}$-(aryl)picolinamides (pic-R) with $\left[\mathrm{Ru}\left(\mathrm{PPh}_{3}\right)_{2}(\mathrm{CO})_{2} \mathrm{Cl}_{2}\right]$ in refluxing 2methoxyethanol in the presence of a base affords hydrido complexes of two types (1-R and 2-R), which are geometric isomers. Similar reaction with $\mathrm{N}$-(naphthyl)picolinamide (pic-nap) yields an organoruthenium complex (3) via formation of a hydrido intermediate. Reaction of 2-(arylazo)phenols (ap- $\mathbf{R})$ with $\left[\operatorname{Ir}\left(\mathrm{PPh}_{3}\right)_{3} \mathrm{Cl}\right]$ in refluxing ethanol affords a mono-hydrido intermediate (4-R), a di-hydrido intermediate (5-R) and an organoiridium complex (6-R) as the final product, where the azo-ligand is coordinated as CNO-donor. Reaction of ap$\mathbf{R}$ ligands with $\left[\mathrm{Rh}\left(\mathrm{PPh}_{3}\right)_{3} \mathrm{Cl}\right]$ yields organorhodium complexes (7-R) analogous to $\mathbf{6}-\mathbf{R}$, but without any hydrido intermediate. $\mathrm{N}-\left(2^{\prime}\right.$-hydroxyphenyl)benzaldimines $(\mathbf{h p b z}-\mathbf{R})$ react with $\left[\mathrm{Rh}\left(\mathrm{PPh}_{3}\right){ }_{3} \mathrm{Cl}\right]$ to yield a group of organorhodium complexes (8-R), where the hpbz-R ligands are coordinated in CNO-fashion. Upon interaction with $\left[\mathrm{Ir}\left(\mathrm{PPh}_{3}\right)_{3} \mathrm{Cl}\right]$ 2-(2',6'-dimethylphenylazo)-4-methylphenol (dmap) undergoes a methyl C-H activation and affords organoiridium complex 9, while 2-(2'-methylphenylazo)-4-methylphenol (mmap) undergoes a phenyl $\mathrm{C}-\mathrm{H}$ activation and gives organoiridium complex 10. Reaction of benzaldehyde thiosemicarbazones (bztsc-R) with $\left[\mathrm{Pd}\left(\mathrm{PPh}_{3}\right)_{2} \mathrm{Cl}_{2}\right]$, carried out with the expectation of inducing CNS-mode of coordination, actually has yielded complexes (11-R) where the bztsc-R is coordinated in an uncommon NS-mode forming a fivemembered chelate ring associated with a restricted rotation around the imine $(\mathrm{C}=\mathrm{N})$ bond. These palladium complexes are found to catalyse $\mathrm{C}-\mathrm{C}$ cross coupling reactions very efficiently. Crystal structures of selected complexes of each type have been determined by X-ray crystallography.
\end{abstract}

Keywords. Organometallic complexes; platinum metals; N-(aryl)picolinamides; 2-(arylazo)-phenols; $\mathrm{N}$-(2'-hydroxyphenyl)benzaldimines; benzaldehyde thiosemicarbazones; crystal structures; catalytic applications.

\section{Introduction}

The chemistry of organometallic complexes has always been receiving special attention, particularly owing to their application in promoting chemical transformation of organic molecules. Formation of a metal-carbon bond usually proceeds through a $\mathrm{C}-\mathrm{H}, \mathrm{C}-\mathrm{C}$ or $\mathrm{C}-\mathrm{X}(\mathrm{X}=$ halogen atom) bond activation step. Choice of suitable organic ligands, as well as appropriate transition metal containing starting materials, is crucial for inducing such bond activation. We have been exploring the chemistry of organometallic complex of platinum metals for last several years, and here we report the summary of some of our selected studies. ${ }^{1-6}$ The primary objective of the present report is to highlight the initial reactions that hinted the possibility of synthesizing organometallic complexes, strategies formulated in order to induce $\mathrm{C}-\mathrm{H}$ bond activation of organic ligands mediated by selected platinum metals, viz. ruthenium, rhodium, iridium and palladium, and finally the reactions which actually led to formation of new organometallic com-

*For correspondence plexes. The results of our attempts in this direction are described in this paper, with special reference to synthesis, structure and catalytic properties.

\section{Experimental}

All the experimental details, with regard to materials, synthesis of complexes, physical measurements and $\mathrm{X}$-ray structure determination, catalytic reactions, are already reported in the literature. ${ }^{1-6}$

\section{Results and discussion}

The present study was initiated with a simple reaction between ruthenium and a group of $\mathrm{N}$-(aryl)picolinamide ligands (pic-R) derived from picolinic acid and para-substituted anilines. As the source of ruthenium, the $\left[\mathrm{Ru}\left(\mathrm{PPh}_{3}\right)_{2}(\mathrm{CO})_{2} \mathrm{Cl}_{2}\right]$ complex was selected, particularly owing to its demonstrated ability to accommodate bidentate ligands through displacement of carbonyl and chloride. The selected amide ligands are known to bind to metal ions in various modes, viz. as mono-anionic NN-donor (I), as mono-anionic 
NO-donor (II) and also as neutral NO-donor (III). The primary objective of this part of the study was to examine the mode of binding to ruthenium. Reactions of the selected amides (pic-R) with $\left[\mathrm{Ru}\left(\mathrm{PPh}_{3}\right)_{2}(\mathrm{CO})_{2} \mathrm{Cl}_{2}\right]$ proceed smoothly in refluxing 2-methoxyethanol in the presence of triethylamine, and from each of these reactions two complexes are obtained, viz. a golden yellow complex (1-R) and a yellow complex (2-R), in moderate yields. Preliminary characterizations on these complexes indicate presence of an amide ligand, two triphenylphosphines, a carbonyl, and a hydride in the coordination sphere. However, to find out the stereochemistry of these complexes and coordination mode of the picolinamide ligand in them, structure of one representative complex from each family, viz. $\mathbf{1 - O C \mathbf { H } _ { 3 }}$ and $\mathbf{2}-\mathbf{C H}_{3}$, has been determined by X-ray crystallography. The structure of $\mathbf{1 - O C H}$ (figure 1) shows that the amide ligand is coordinated to the metal centre, via dissociation of the $\mathrm{N}-\mathrm{H}$ proton, as monoanionic NN-donor (I) and, two triphenylphosphines, a hydride and a carbonyl are also coordinated to ruthenium. The coordinated picolinamide, hydride and carbonyl constitute one equatorial plane with the metal at the centre, where the hydride is trans to the pyridine-nitrogen and the carbonyl is trans to the amide-nitrogen. The $\mathrm{PPh}_{3}$ ligands have occupied the remaining two axial positions and hence they are mutually trans. The structure of $\mathbf{2}-\mathbf{C H}_{\mathbf{3}}$ (figure 2) shows that

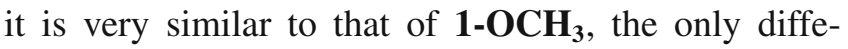
rence is in the disposition of coordinated carbonyl and hydride with respect to the coordinated picolinamide. The hydride is trans to the amide-nitrogen and the carbonyl is trans to the pyridine-nitrogen. Formation of the

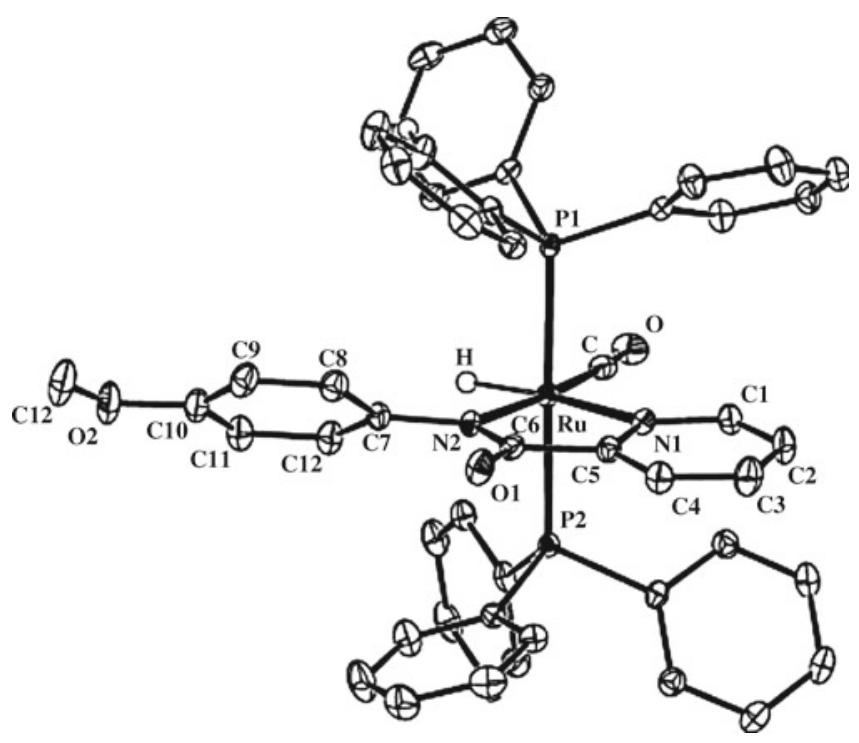

Figure 1. View of the 1-OCH $\mathbf{C H}_{3}$ complex.

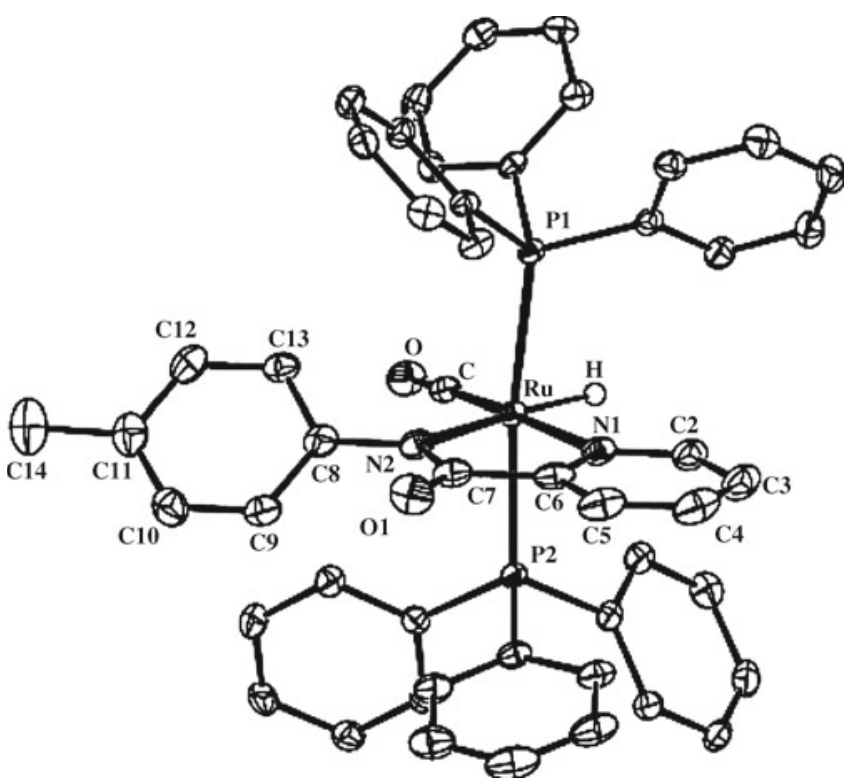

Figure 2. View of the 2- $\mathbf{C H}_{3}$ complex.

two stereoisomers (1-R and $\mathbf{2}-\mathbf{R})$ from the same reaction has been quite interesting, and some speculated steps, that seem probable, are shown in scheme 1. In the initial step, the amide ligand (pic-R) is believed to bind to the metal centre, via dissociation of the acidic N$\mathrm{H}$ proton, as mono-anionic NN-donor, with simultaneous dissociation of a $\mathrm{CO}$ and a chloride from the ruthenium starting complex, to generate two stereoisomers (A and B) of an intermediate, probably via different kinetic routes. The ruthenium-bound chloride in these intermediates reacts with the solvent and thus leads to formation of a $\mathrm{Ru}-\mathrm{H}$ fragment affording the 1-R and 2-R complexes, respectively.
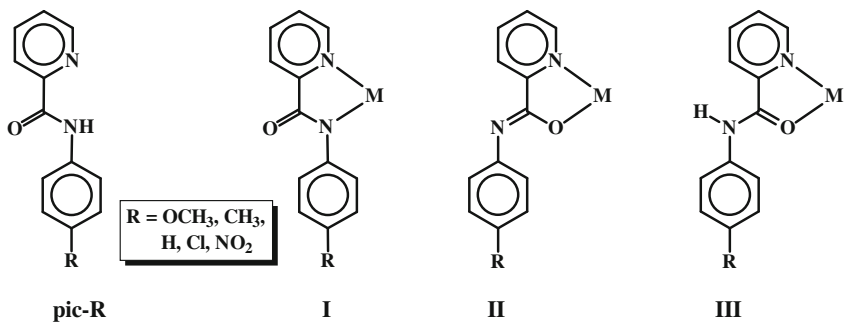

Disposition of the $\mathrm{Ru}-\mathrm{H}$ bond with respect to the pendent phenyl ring in $\mathbf{1 - R}$ points to the possibility of a $\mathrm{C}-\mathrm{H}$ activation of the aryl ring, which could not take place in the $\mathbf{1 - R}$ complexes as the phenyl ring is not close enough to the $\mathrm{Ru}-\mathrm{H}$ fragment. However, it was understood that in order to undergo $\mathrm{C}-\mathrm{H}$ activation the aryl fragment should be so chosen that one of its $\mathrm{C}-\mathrm{H}$ bonds can come in close proximity to the $\mathrm{Ru}-\mathrm{H}$ bond. With this sim- 


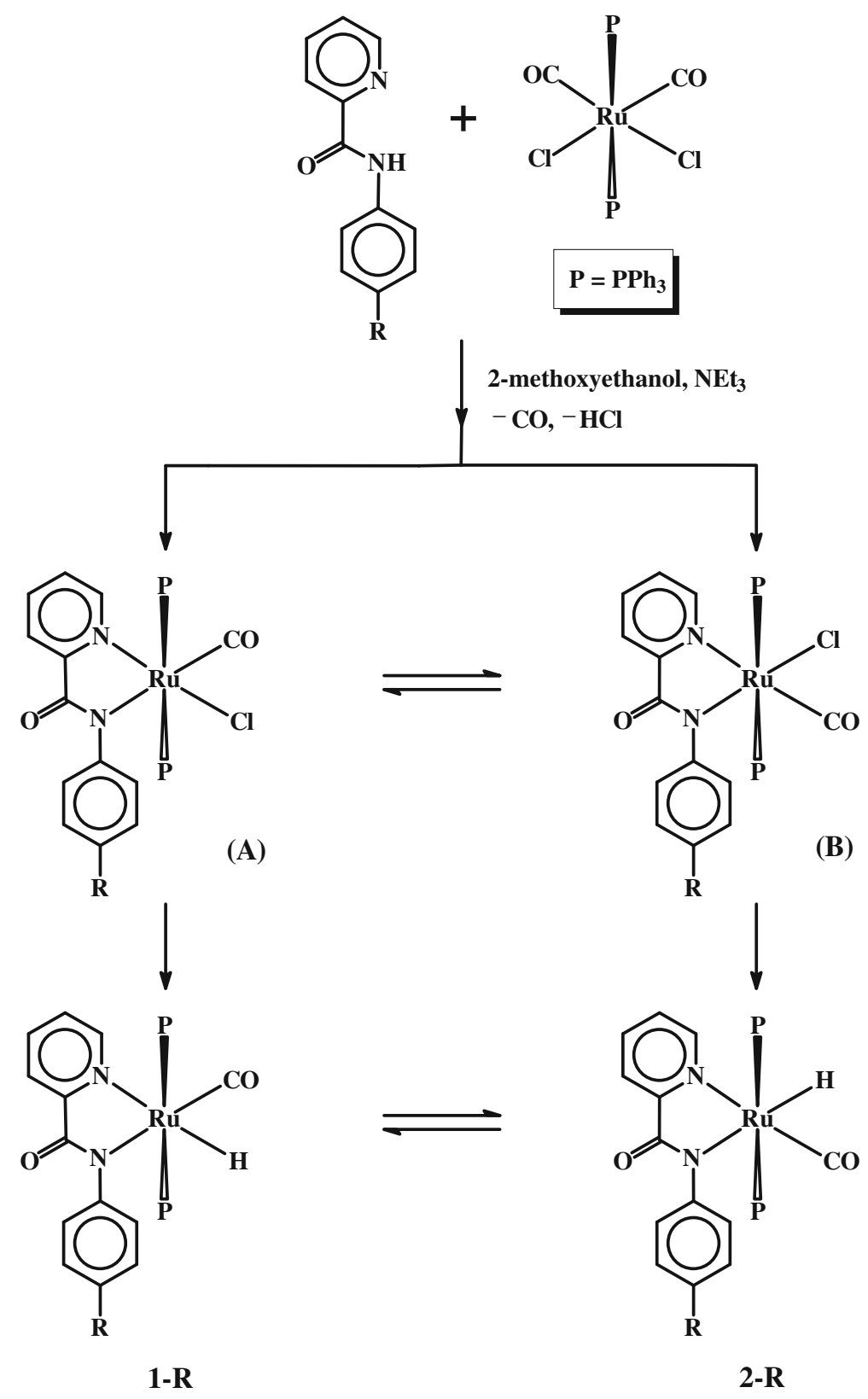

Scheme 1. Probable steps behind formation of the $\mathbf{1 - R}$ and $\mathbf{2}-\mathbf{R}$ complexes.

ple strategy in mind, $\mathrm{N}$-(naphthyl)picolinamide (picnap) has been chosen as the modified amide ligand for the targeted $\mathrm{C}-\mathrm{H}$ activation. Reaction of pic-nap with $\left[\mathrm{Ru}\left(\mathrm{PPh}_{3}\right)_{2}(\mathrm{CO})_{2} \mathrm{Cl}_{2}\right]$, carried out similarly as before, has afforded an orange complex (3) containing an amide ligand, two triphenylphosphines and a carbonyl, but no hydride. Structure determination of complex $\mathbf{3}$ by X-ray crystallography (figure 3) shows that $\mathrm{N}$-(naphthyl)picolinamide is indeed coordinated to ruthenium in the expected NNC-fashion (IV). The coordinated carbonyl is sharing the same equatorial plane with the amide ligand and the two $\mathrm{PPh}_{3}$ ligands are trans as before. Probable sequences behind formation of the cyclometalated complex $\mathbf{3}$ are illustrated in scheme 2. As before, an equilibrium mixture of two stereoisomers ( $\mathbf{C}$ and $\mathbf{D})$ of a hydride intermediate are formed initially, in both of which the amide ligand is coordinated in $\mathrm{NN}$-fashion. Isomer $\mathbf{C}$ of the intermediate then undergoes the $\mathrm{C}-\mathrm{H}$ activation at the 8-position of the naphthyl ring affording the cyclometalated species $\mathbf{3}$ via elimination of molecular hydrogen. As isomer $\mathbf{C}$ is irreversibly transformed into the cyclometalated species $\mathbf{3}$, the equilibrium between the two isomers gradually shifts towards $\mathbf{C}$, and thus the cyclometalated species $\mathbf{3}$ is obtained as the sole product from this reaction. This particular exercise thus demon- 


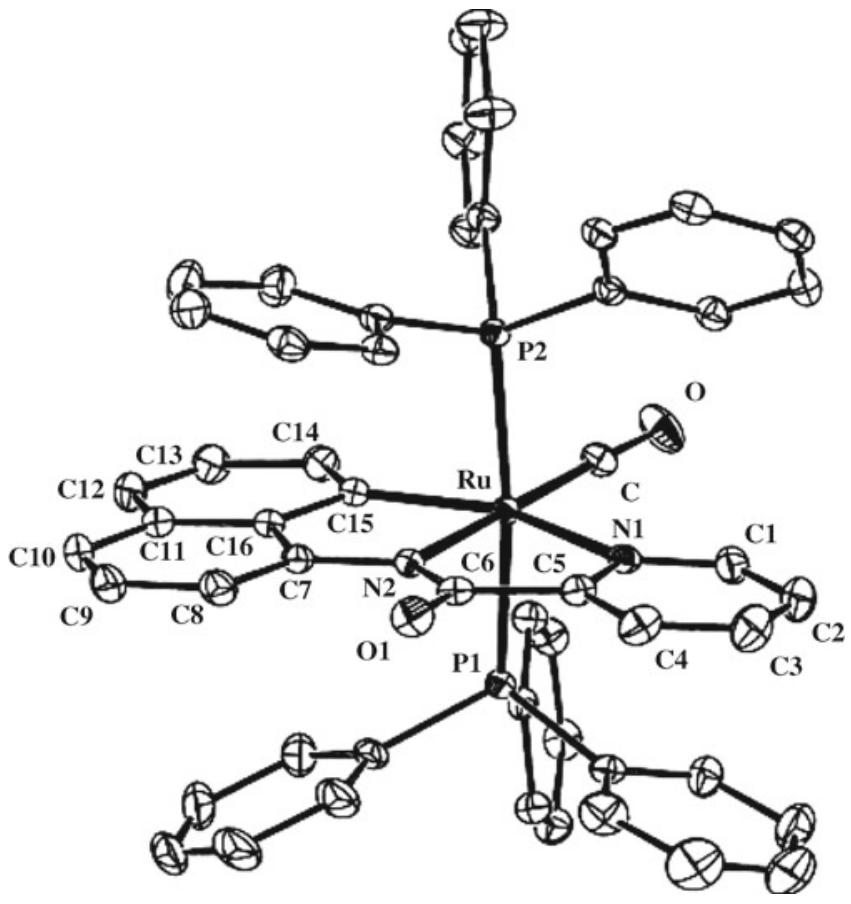

strates that $\mathrm{Ru}-\mathrm{H}$ fragment can efficiently activate proximal aryl $\mathrm{C}-\mathrm{H}$ bond. ${ }^{1}$<smiles>O=C(Nc1cccc2ccccc12)c1ccccn1</smiles>

pic-nap

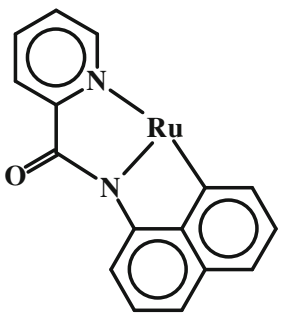

IV
The success in $\mathrm{C}-\mathrm{H}$ bond activation of $\mathrm{N}$ (naphthyl)picolinamide (pic-nap), mediated by ruthenium, has encouraged us to explore similar activation reactions utilizing other platinum metals. In this perspective, we have studied the interaction between a group of 2-(arylazo)phenols (ap-R) and iridium. As the source of iridium $\left[\operatorname{Ir}\left(\mathrm{PPh}_{3}\right)_{3} \mathrm{Cl}\right]$ has been selected,

Figure 3. View of the complex 3 .

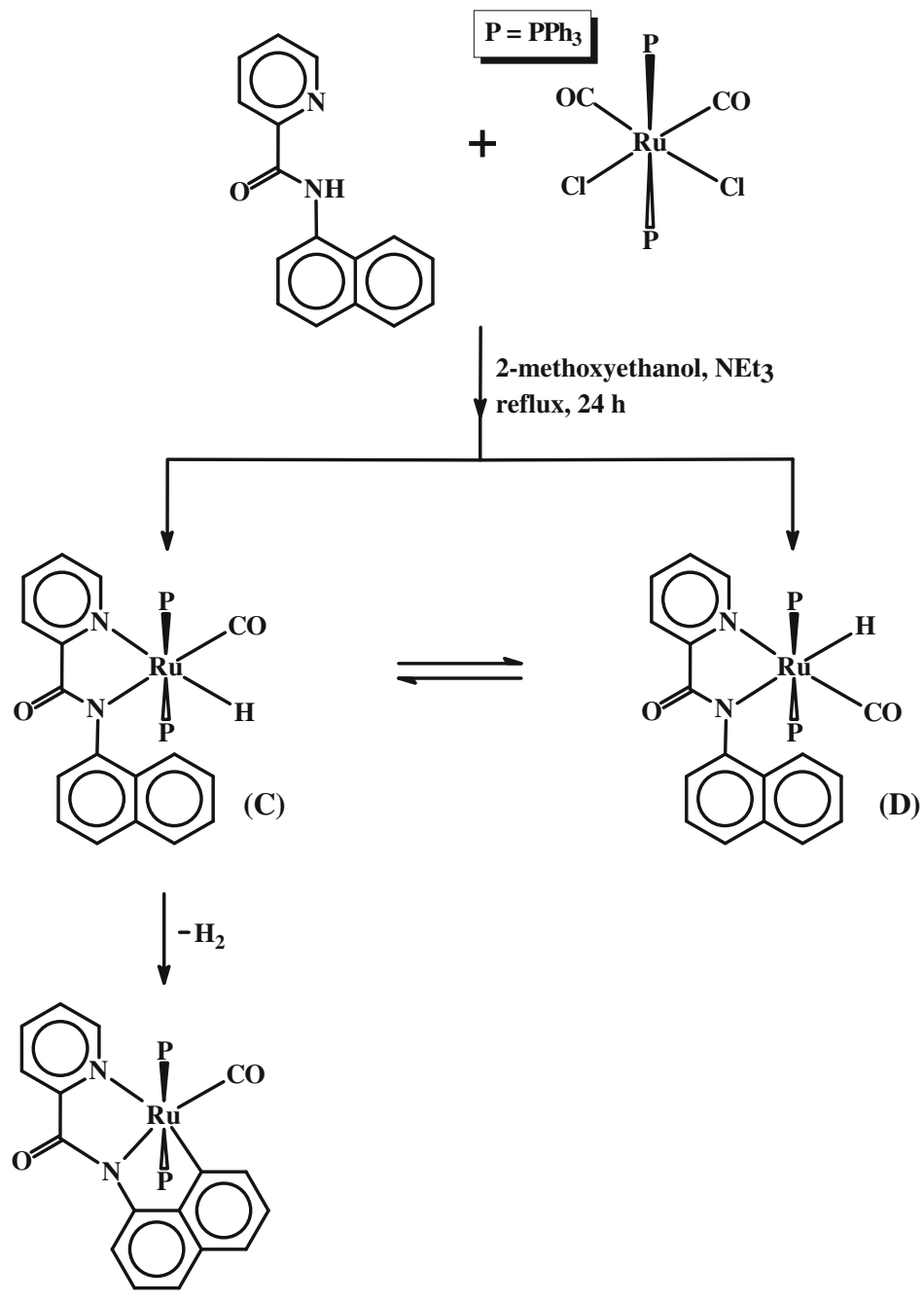

Scheme 2. Probable steps behind formation of the complex 3 . 
particularly because of its ability to undergo oxidative insertion into acidic bonds. Reaction of the chosen ap-R ligands with $\left[\operatorname{Ir}\left(\mathrm{PPh}_{3}\right)_{3} \mathrm{Cl}\right]$ in ethanol resulted in the formation of complexes of three different types with distinctly different colours, viz. purple (4-R), pink (5-R) and blue (6-R). Crystal structures of 4-Cl, 5-Cl and 6-Cl have been determined (figures 4-6). The structures show that in the 4- $\mathbf{R}$ complexes the ap- $\mathbf{R}$ ligand is coordinated as mono-anionic NO-donor (V) along with two $\mathrm{PPh}_{3}$ ligands, a hydride and a chloride. The $\mathbf{5 - R}$ complexes are similar to the corresponding 4-R complexes, except that a hydride is coordinated to iridium in $\mathbf{5 - R}$ instead of the chloride in 4-R. In 6-R, the ap-R ligand is coordinated as di-anionic CNO-donor (VI) along with two $\mathrm{PPh}_{3}$ ligands and a hydride. It is believed that formation of these three types of complexes takes place sequentially, which is shown in scheme 3 .
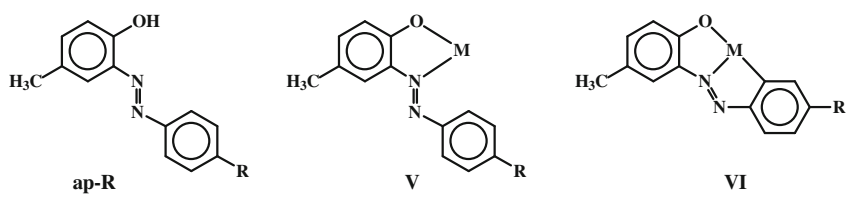

This speculation is backed up by the observation that any isolated purple $\mathbf{4 - R}$ complex is gradually converted into the corresponding pink $\mathbf{5}-\mathbf{R}$ complex upon standing in alcoholic medium in the presence of a base. Similarly, alcoholic solution of any isolated pink 5-R complex gradually gets transformed into the corresponding blue 6-R complex. It thus becomes quite apparent that

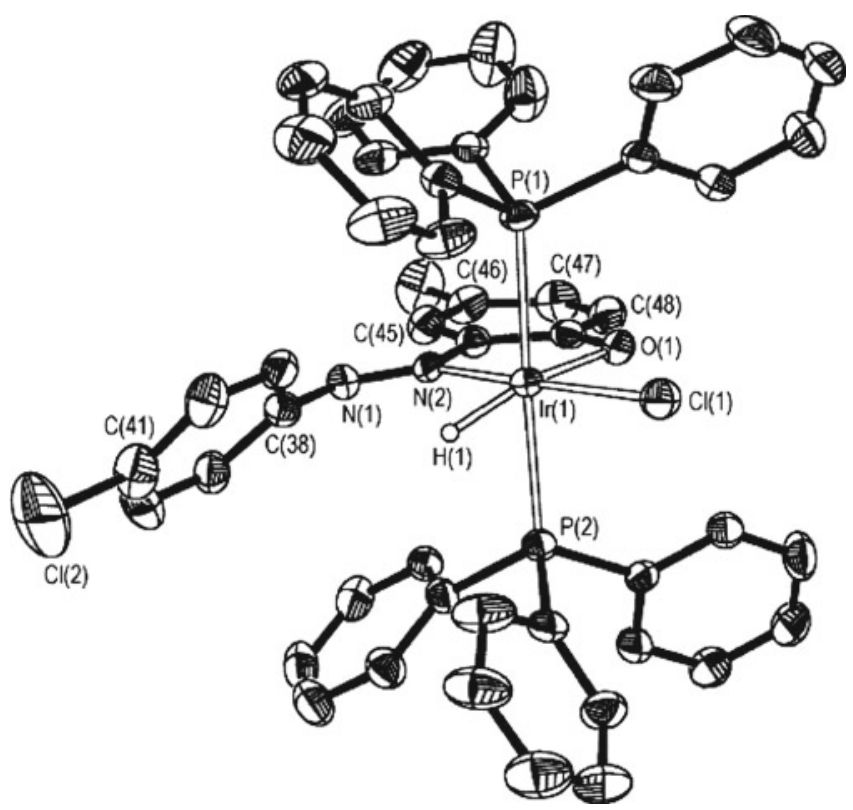

Figure 4. View of the 4-Cl complex.

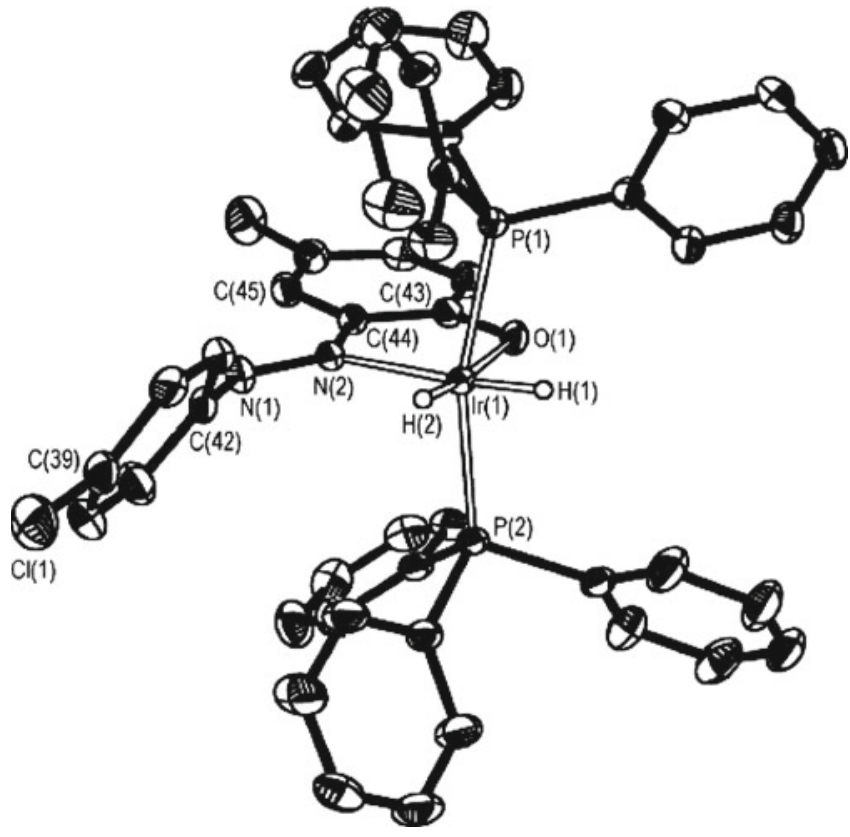

Figure 5. View of the 5-Cl complex.

Ir-H bond can also successfully bring about activation of proximal aryl $\mathrm{C}-\mathrm{H}$ bond. ${ }^{2}$

Prompted by the above observations, we have also carried out similar reaction of the same group of 2(arylazo)phenols (ap-R) with $\left[\mathrm{Rh}\left(\mathrm{PPh}_{3}\right)_{3} \mathrm{Cl}\right]$. The reactions proceed smoothly in refluxing toluene and afford the expected organorhodium complexes (7-R). However, no intermediate could be isolated from the reaction. Crystal structure of $\mathbf{7 -} \mathbf{N O}_{\mathbf{2}}$ has been determined (figure 7), which shows that the ap-R ligand is coordi-

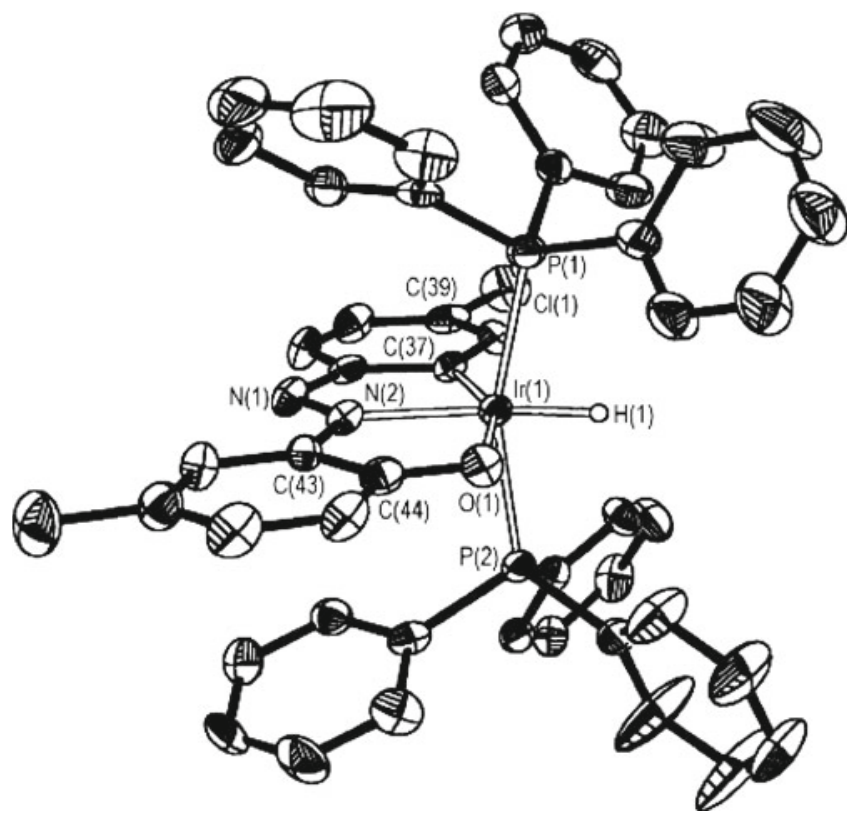

Figure 6. View of the 6-Cl complex. 

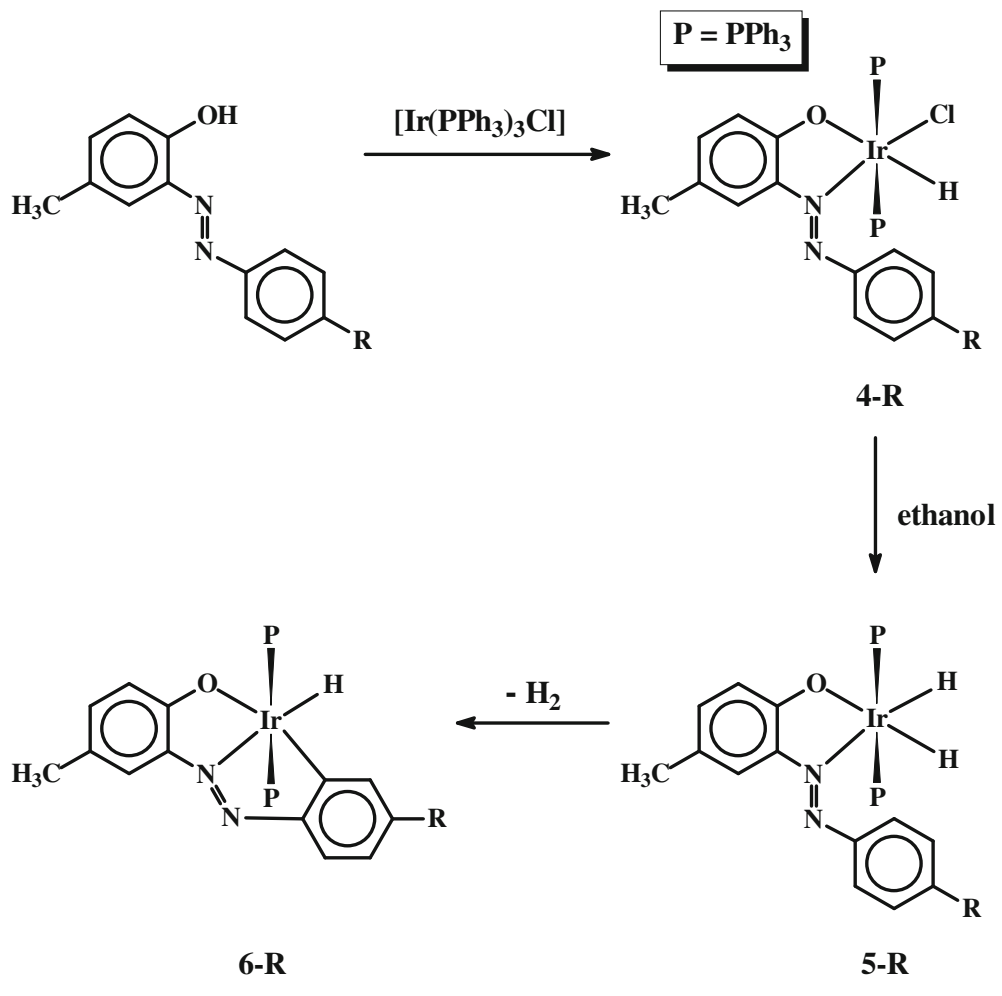

Scheme 3. Steps behind formation of complexes 4-R, 5-R and 6-R.

nated to rhodium as di-anionic $\mathrm{CNO}$-donor (VI) along with two $\mathrm{PPh}_{3}$ ligands and a chloride. It is believed that a hydrido intermediate (analogous to the 4-R complex in scheme 3 ) is generated initially, which is rapidly transformed into the cyclometallted species (7-R) via elimination of molecular hydrogen. This exercise thus indicates that the $\mathrm{Rh}-\mathrm{H}$ bond, formed in situ, is very

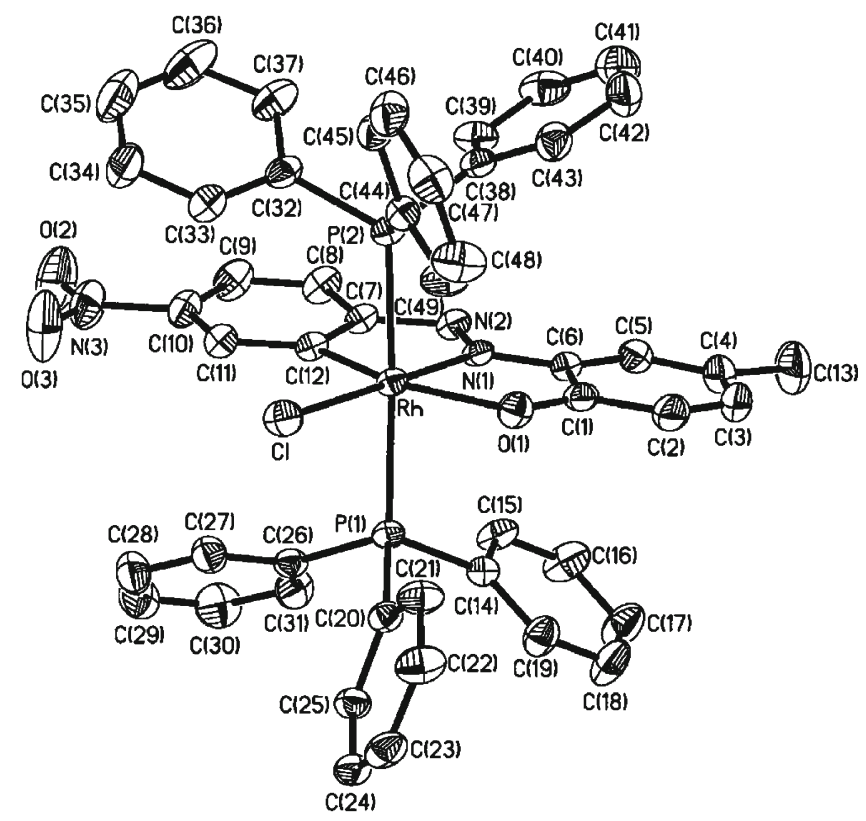

Figure 7. View of the 7-NO $\mathrm{NO}_{2}$ complex. reactive and it can also be utilized to activate aryl $\mathrm{C}-\mathrm{H}$ bond leading to formation of interesting organorhodium complexes. ${ }^{3}$

Using the same strategy as before, reaction of a group of Schiff base ligands, viz. N-(2'-hydroxyphenyl)benzaldimines (hpbz-R), derived from 2-aminophenol and para-substituted benzaldehydes, has been carried out with $\left[\mathrm{Rh}\left(\mathrm{PPh}_{3}\right)_{3} \mathrm{Cl}\right]$. These ligands have been chosen as they have skeletal similarity with the 2-(arylazo)phenols (ap-R). A group of organorhodium complexes (8R) have been obtained from these reactions (scheme 4), as expected. ${ }^{4}$ Crystal structure of $\mathbf{8 - \mathbf { O C H } _ { 3 }}$ complex has been solved (figure 8), which confirmed the CNOmode of binding of the apbz-R ligand. The two triphenylphosphines are again mutually trans in this complex, and the coordinated chloride is found to share the equatorial plane with the CNO-coordinated ligand. Formation of these organorhodium $\mathbf{8 - R}$ complexes is

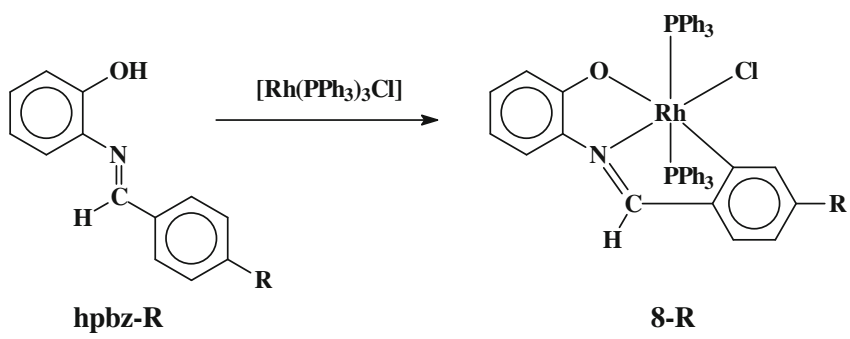

Scheme 4. Formation of 8-R complexes. 


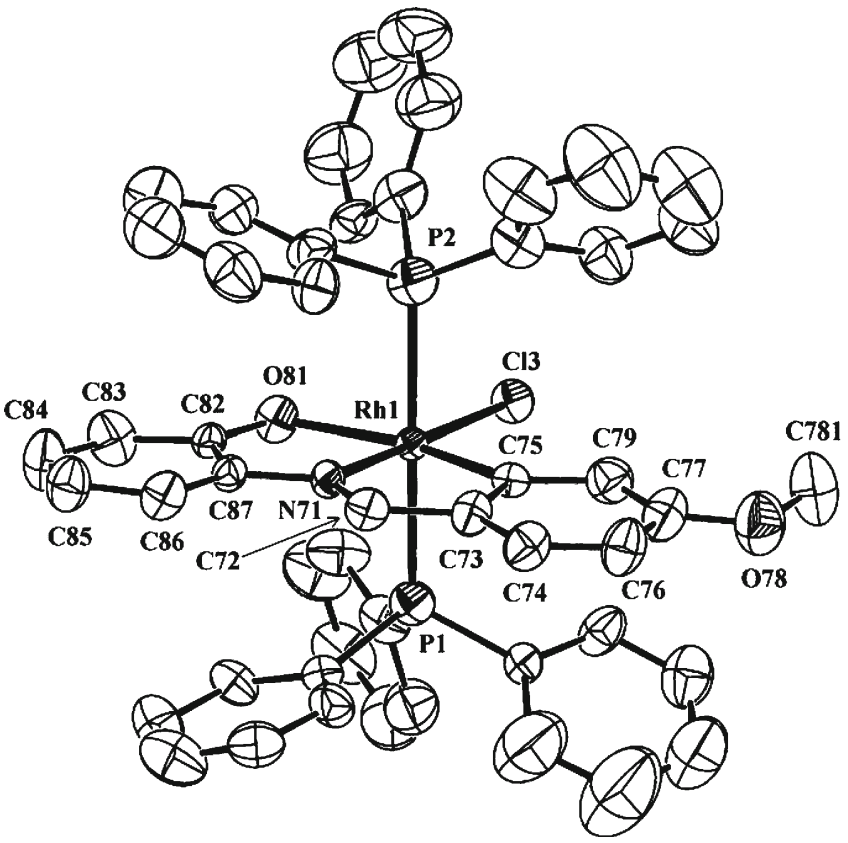

Figure 8. View of the 8-OCH $\mathbf{C H}_{3}$ complex.

also believed to pass through the intermediacy of a hydrido-rhodium complex.

The observation, that the 2-(arylazo)phenols (ap-R) can undergo facile orthometallation reactions affording interesting organometallic complexes, has encouraged us to examine the fate of similar ligands where both the ortho positions of the phenyl ring in the arylazo fragment are blocked by alkyl groups. For this purpose, a modified 2-(arylazo)phenol, viz. 2-(2',6'dimethylphenylazo)-4-methylphenol (dmap), has been

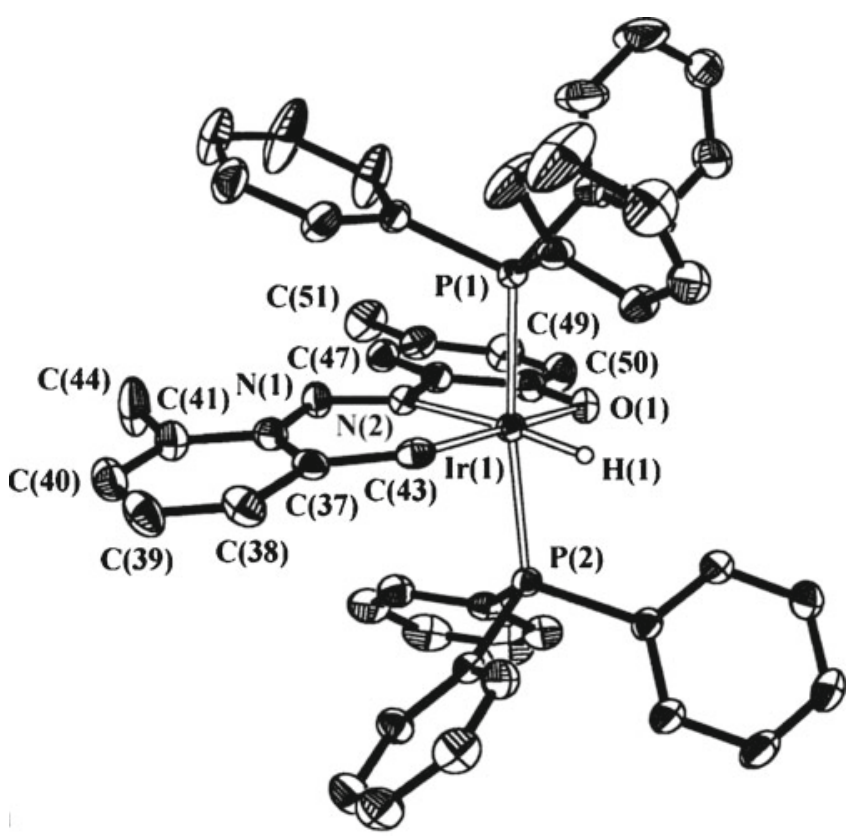

Figure 9. View of the complex 9.

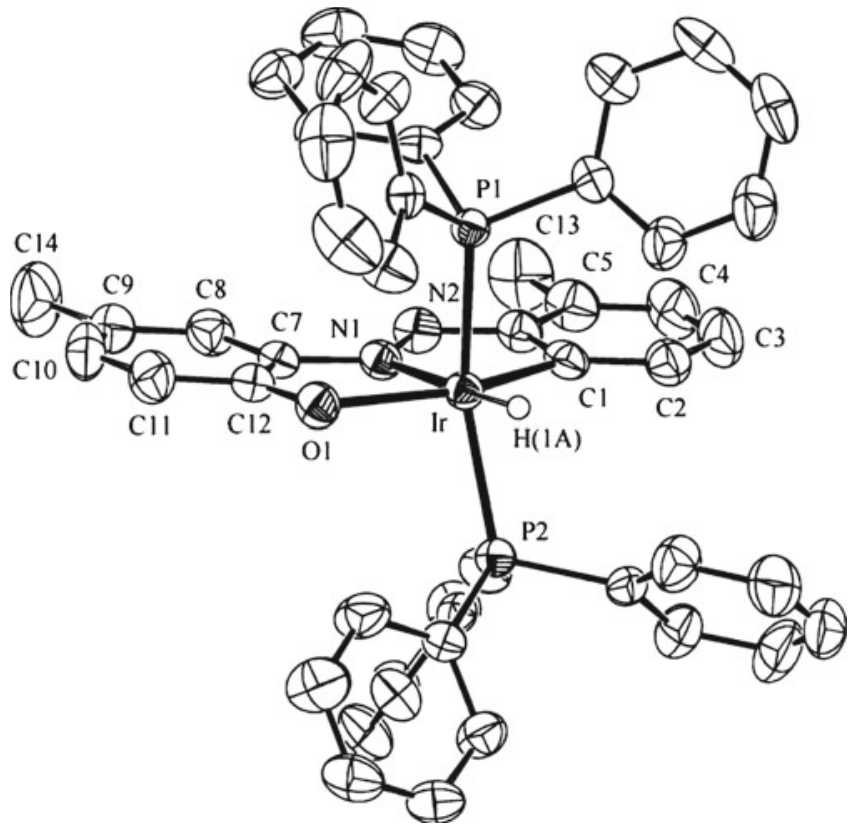

Figure 10. View of the complex 10.

selected. Reaction of this new azo-ligand (dmap) has been carried out with $\left[\operatorname{Ir}\left(\mathrm{PPh}_{3}\right)_{3} \mathrm{Cl}\right]$, which afforded a pink complex 9. Structure determination of this complex 9 by X-ray crystallography (figure 9) shows that the dmap ligand has undergone a methyl $\mathrm{C}-$ $\mathrm{H}$ activation during the course of this reaction and is coordinated to iridium in ONC-mode (VII). To test the preference, if any, between methyl C$\mathrm{H}$ activation and phenyl $\mathrm{C}-\mathrm{H}$ activation, we have next chosen another azo-phenol ligand, viz. 2-( $2^{\prime}-$ methylphenylazo)-4-methylphenol (mmap), in which only one ortho position of the phenyl ring in the arylazo fragment is blocked by a methyl group while the other ortho position is still unsubstituted. This

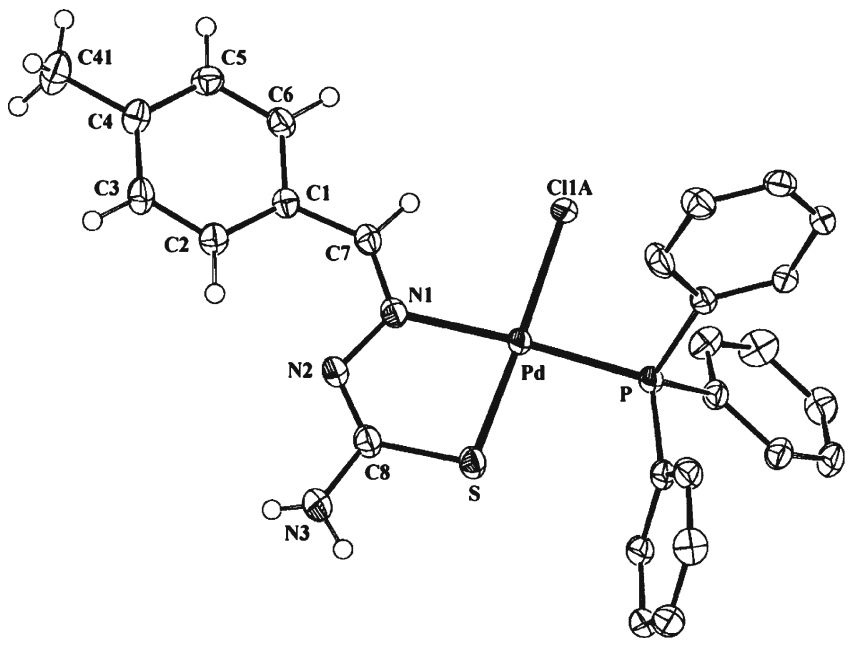

Figure 11. View of the 11- $\mathbf{C H}_{\mathbf{3}}$ complex. 


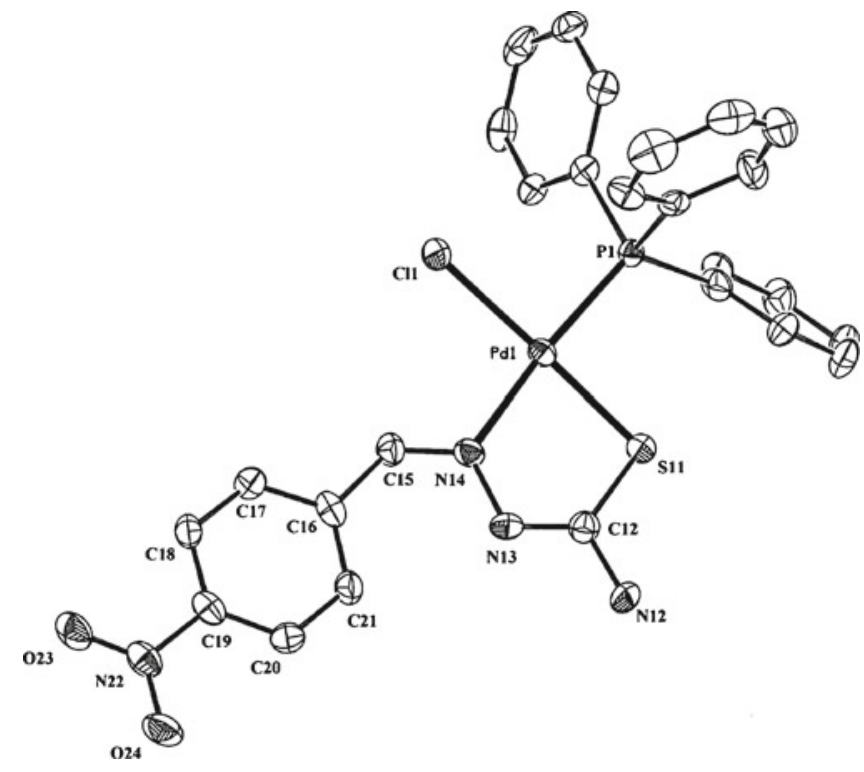

Figure 12. View of the $\mathbf{1 1 - \mathbf { N O } _ { 2 }}$ complex.

mmap ligand, in principle, may show both the types of $\mathrm{C}-\mathrm{H}$ bond activation (VIII and IX). Reaction of this mmap ligand, carried out with $\left[\operatorname{Ir}\left(\mathrm{PPh}_{3}\right)_{3} \mathrm{Cl}\right]$ in a similar fashion as before, has afforded a blue complex 10. Structure determination of this complex $\mathbf{1 0}$ by X-ray crystallography (figure 10) shows that the mmap ligand has actually undergone a phenyl $\mathrm{C}-\mathrm{H}$ activation during the course of this reaction and is coordinated to iridium in ONC-mode (IX). Hence, it is indicated that if option between methyl and phenyl $\mathrm{C}-\mathrm{H}$ activations is available, the latter takes place preferentially. However, under unavoidable condition, as has been the case with the dmap ligand, methyl $\mathrm{C}-\mathrm{H}$ activation definitely takes place. ${ }^{5}$<smiles>Cc1ccc(O)c(/N=N/c2c(C)cccc2C)c1</smiles><smiles>Cc1ccc2c(c1)N1N=Nc3c(C)cccc3CC2O1</smiles>

VII<smiles>Cc1ccc(O)c(NCc2ccccc2C)c1</smiles><smiles>Cc1ccc2c(c1)N1Cc3ccccc3CN1C2</smiles><smiles>Cc1ccc2c(c1)NC1ON(C2)c2c(C)cccc21</smiles>

Finally, we have scrutinized the possibility of $\mathrm{C}-\mathrm{H}$ bond activation of a group of benzaldehyde thiosemicarbazones (bztsc-R) using palladium as the metal centre. In addition to their ability to serve as monoanionic bidentate NS-donor, these ligands also have the potential to undergo orthometallation and display a CNS-mode of coordination $(\mathbf{X})$. With an intention to achieve this CNS-mode of binding, reactions of the selected thiosemicarbazones have been carried out with $\left[\mathrm{Pd}\left(\mathrm{PPh}_{3}\right)_{2} \mathrm{Cl}_{2}\right]$, taken as the palladium starting material, which yielded a group of yellow complexes (11$\mathbf{R})$. However, structure determination of $\mathbf{1 1}-\mathbf{C H}_{3}$ by X-ray crystallography (figure 11) shows that instead

Table 1. Suzuki cross coupling of aryl bromides with phenylboronic acid. ${ }^{\mathrm{a}}$

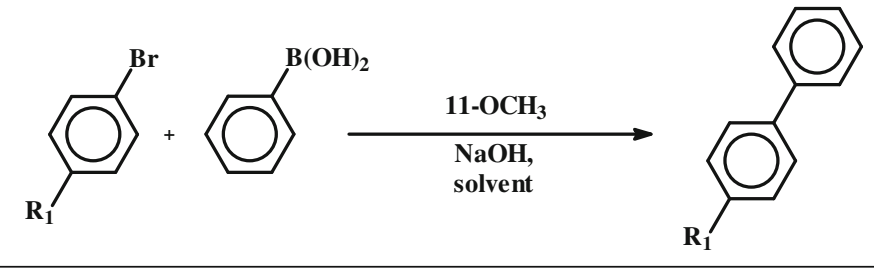

\begin{tabular}{|c|c|c|c|c|c|c|c|}
\hline Entry & $\mathrm{R}_{1}$ & Solvent & Temp, ${ }^{\circ} \mathrm{C}$ & Time (h) & Amt of cat., mol\% & Conversion, ${ }^{\mathrm{b}} \%$ & $\mathrm{TON}^{\mathrm{c}}$ \\
\hline 1 & $\mathrm{COCH}_{3}$ & Ethanol-toluene (1:1) & 95 & 9 & 0.001 & $>99$ & 100000 \\
\hline 2 & $\mathrm{CHO}$ & Ethanol-toluene $(1: 1)$ & 95 & 12 & 0.001 & $>99$ & 100000 \\
\hline 3 & $\mathrm{CN}$ & Ethanol-toluene (1:1) & 95 & 12 & 0.001 & $>99$ & 100000 \\
\hline 4 & $\mathrm{COCH}_{3}$ & Ethanol-toluene (1:1) & 25 & 20 & 0.001 & $>99$ & 100000 \\
\hline 5 & $\mathrm{COCH}_{3}$ & Water & 100 & 12 & 1 & $>99$ & 100 \\
\hline
\end{tabular}

${ }^{a}$ Reaction conditions: aryl bromide $(1.0 \mathrm{mmol})$, phenylboronic acid $(1.2 \mathrm{mmol}), \mathrm{NaOH}(1.7 \mathrm{mmol}), \mathrm{Pd}$ catalyst, solvent $(4 \mathrm{~mL})$.

${ }^{b}$ Determined by ${ }^{1} \mathrm{H}$ NMR on the basis of residual aryl halide.

${ }^{\mathrm{c}} \mathrm{TON}=$ turnover number $((\mathrm{mol}$ of product $) /(\mathrm{mol}$ of catalyst $))$ 
of binding palladium in the expected CNS-mode, the thiosemicarbazone is actually coordinated to the metal centre in a rather uncommon NS-mode (XI) forming a five-membered chelate ring associated with a restricted rotation around the imine $(\mathrm{C}=\mathrm{N})$ bond.
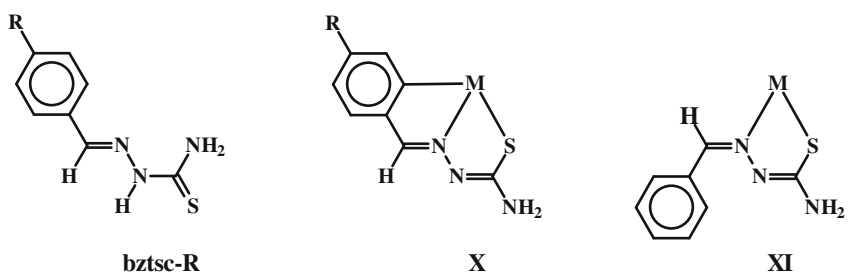

To ensure that the same mode of binding of thiosemicarbazone is existing in all these 11-R complexes, crystal structure of another member of this family, viz. 11$\mathbf{N O}_{2}$, has also been solved, and the structure (figure 12) is found to be similar in every respect to that of the 11- $\mathbf{C H}_{3}$ complex.

Due to the restricted rotation around the imine $(\mathrm{C}=\mathrm{N})$ bond, which has occurred during formation of the five-membered chelate ring in these 11-R complexes, the phenyl group has moved away from the metal centre, and this vitiates the possibility of the expected cyclopalladation. Hence this exercise has been slightly disappointing. However, this disappointment has been partially compensated by the remarkable catalytic properties exhibited by these palladium complexes towards $\mathrm{C}-\mathrm{C}$ cross coupling reactions of three different types, viz. Suzuki, Heck and Sonogashira coupling. ${ }^{6}$ For example, the 11- $\mathbf{O C H}_{3}$ complex has been found to catalyse Suzuki coupling reaction between parasubstituted phenyl bromides and phenylboronic acid with great efficiency (entries 1-3, table 1), with particular reference to relatively mild experimental condi- tions, the absence of any external ligand, very low catalyst loading and high turnover numbers. Such coupling reactions are also found to be possible at room temperature (entry 4), as well as in aqueous medium (entry 5) with slight modification of the reaction parameters.

\section{Conclusions}

The present study shows that organometallic complexes of the platinum metals can be conveniently synthesized via $\mathrm{C}-\mathrm{H}$ bond activation mediated by a $\mathrm{M}-\mathrm{H}$ or $\mathrm{M}-$ $\mathrm{Cl}$ fragment $(\mathrm{M}=$ platinum metal). This study also demonstrates that aryl $\mathrm{C}-\mathrm{H}$ bond activation is much more facile compared to alkyl $\mathrm{C}-\mathrm{H}$ bond activation.

\section{Acknowledgements}

Authors thank the funding agencies and all the coauthors associated with the six papers cited as references 1-6.

\section{References}

1. Nag S, Butcher R J and Bhattacharya S 2007 Eur. J. Inorg. Chem. 1251

2. Acharyya R, Basuli F, Wang R Z, Mak T C W and Bhattacharya S 2004 Inorg. Chem. 43704

3. Dutta S, Peng S M and Bhattacharya S 2000 J. Chem. Soc. Dalton Trans. 4623

4. Basu S, Dutta S, Drew M G B and Bhattacharya S 2006 J. Organomet. Chem. 6913581

5. Acharyya R, Basuli F, Peng S M, Lee G H, Wang R Z, Mak T C W and Bhattacharya S 2005 J. Organomet. Chem. 6903908

6. Paul P, Datta S, Halder S, Acharyya R, Basuli F, Butcher R J, Peng S M, Lee G H, Castineiras A, Drew M G B and Bhattacharya S 2011 J. Mol. Cat. A 34462 